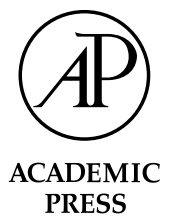

\title{
The effects of near wins and near losses on self-perceived personal luck and subsequent gambling behavior ${ }^{\text {负 }}$
}

\author{
Michael J.A. Wohl and Michael E. Enzle* \\ Department of Psychology, University of Alberta, P-217 Biological Sciences Building, Edmonton, Alta., Canada T6G 2E1
}

Received 11 June 2001; revised 15 March 2002

\begin{abstract}
Which person would be most likely to continue gambling? A person who has just experienced a big win or a person who has just experienced a big loss? The answer appears often to be whichever gambler feels personally luckier. Two experiments investigated how perceptions of luck, understood as a personal quality, are affected by near, but unrealized outcomes during a game of chance. In Experiment 1, a near big loss at a gambling game heightened perceptions of personal luck relative to a near big win, even though all participants actually won the same modest amount. In addition, participants who experienced a near big loss generated significantly more downward counterfactuals than did those participants in the near big win condition. Most importantly, differences in selfperceived luck influenced future gambling behavior. Participants who experienced a near big loss on a wheel-of-fortune wagered significantly more on the outcome of a subsequent game of roulette than did those participants who experienced a near big win. Experiment 2 extended these results by testing the possible influence of a different type of near outcome and by including a control group. The discussion focuses on the emerging picture of how people understand luck.
\end{abstract}

(c) 2002 Elsevier Science (USA). All rights reserved.

Two gamblers find themselves playing adjacent slot machines. Each of them places his or her last dollar into the respective machines and watch as the wheels rapidly spin. The wheels gradually stop; one machine nearly misses JACKPOT (\$70), and the other machine nearly misses BANKRUPT. In the end, both wheels land on a modest win $(\$ 10)$. The gamblers have now equally increased their investments. Which gambler, however, will be more likely to gamble again? The answer to this question is a key one for understanding gambling be-

\footnotetext{
The research was supported in part by a Social Sciences and Humanities Research Council of Canada Doctoral Fellowship (\#7522000-1333) to the first author, a research grant from the Social Sciences and Humanities Research Council of Canada (\#410-92-0464) to the second author, and a research grant from the Alberta Gaming Research Institute to both authors. Portions of this research were presented at the Meeting of the Midwestern Psychological Association in Chicago, May 2001. The authors are indebted to Keith Markman for his valuable suggestions about Experiment 2, and to Tom Johnson and Christina Gagne for their statistical advice.

${ }^{*}$ Corresponding author.

E-mail address: mike.enzle@ualberta.ca (M.E. Enzle).
}

havior. Future behavior is preceded not only by actual wins and losses, but by near wins and near losses.

\section{Counterfactual thinking}

Our hypothetical scenario is usually understood in terms of the counterfactual thinking approach (see Roese, 1997 for a review). Indeed, the basic elements of counterfactual thought are present. Both of our gamblers could easily imagine an alternative outcome to the one that they actually experienced. One type of counterfactual thinking (upward) involves the mutation of events so that a better than observed outcome is imagined, and its opposite (downward) involves the mutation of events so that a worse than observed outcome is imagined (e.g., Markman, Gavanski, Sherman, \& McMullen, 1993, 1995; Roese, 1994; Sanna, 1996). Our near big winner likely wishes during the spin that he will land on Jackpot; that easily imagined, but unattained outcome, forms the basis for an upward counterfactual. Our near big loser, on the other hand, wishes that the wheel will not stop on the Bankrupt section; the easily 
imagined but avoided big loss then becomes the basis for the downward counterfactual.

\section{Luck as a personal quality and games of chance}

Although the counterfactual approach is helpful in understanding the cognitive outcomes of near events, we believe that the information conveyed by near events, in games of pure chance, may also affect people's likelihood of continued or future gambling. We believe that self-perceived luck influences gambling behavior, and that near big losers, paradoxically, feel luckier than near big winners.

Our prediction derives from the proposition that people understand luck as a personal quality (Darke \& Freedman, 1997; Wohl \& Enzle, 2002). Theories in social cognition generally approach luck as an aspect of the external world (e.g., Weiner, 1974). People are assumed to understand that the roll of dice, the fall of a roulette ball, and the outcome of a slot machine are outside of their control. Good luck then occurs when randomness produces a good outcome for the gambler, and bad luck occurs when it produces losses. There is evidence, however, that people sometimes understand luck differently than the traditional psychological conceptualization. For example, Wagenaar and Keren (1988) have shown that people conceptually distinguish between chance events and what we refer to as personal luck, with the former term capturing the situational aspect of random events, and the latter term capturing people's belief in a deployable personal (or dispositional) skill. Elsewhere, we have suggested that people's estimates of their personal luck are influenced by contextual variables (Wohl \& Enzle, 2002). We predicted and found, in an illusion of control paradigm, that people's beliefs in personal luck were heightened when they were able to make choices relevant to a pure game of chance (selecting a lottery ticket) even though that choice had no causal connection to the outcome of the game. Thus, situational events can affect the amount of personal luck that people believe they possess.

To the extent that a person views himself or herself as personally lucky, subsequent betting behavior should increase. Estimates of how much luck people believe they possess should be the result of familiar person perception processes. Returning to our originating example, we believe that the person who nearly missed the Bankrupt outcome on the slot machine play will feel luckier, and subsequently be more likely to gamble, than the person who nearly missed the Jackpot. The near big loser who has wished for the avoidance of what appeared an imminent loss should perceive his or her personal luck to have been responsible for avoiding the bad outcome (and should generate a downward counterfactual). On the other hand, a person who wished for the Jackpot, and who nearly experienced it, should perceive him- or herself to be relatively unlucky (and should generate an upward counterfactual). The net effect, then, is that the person who nearly lost should feel personally luckier and should bet more than the person who nearly won.

It is interesting to note that if we were to ignore the implications of near experiences for self-perceived personal luck, the counterfactual thinking approach might suggest a different set of predictions (e.g., Markman \& Tetlock, 2000; McMullen \& Markman, 2000; Sanna, 1996, 1998). Generally speaking, theorists have assumed that the processes involved in upward counterfactuals serve a better preparative function than do those involved in downward counterfactuals (see Johnson \& Sherman, 1990; Roese, 1994). A straightforward adaptation of the hypothesized preparatory function of upward counterfactuals would be that the gambler who nearly missed the big payoff (and hence sees a better possible world) would increase his or her gambling behavior. But there is a problem with this adaptation to games of pure chance. Research showing that upward counterfactuals are linked to better subsequent performance is based on the premise that perceived better possible worlds lead to increased effort and practice. This argument is reasonable in situations where conventional skills can be improved via effort and practice. However, in games of pure chance, no amount of practice or increased effort will improve the gambler's chances at attaining a big payoff, regardless of people's perceptions to the contrary (cf. Langer, 1975).

\section{Experiment 1: Personal luck and gambling behavior}

In Experiment 1, we tested the hypothesis that near big losses result in more extreme perceptions of personal luck than do near big wins in purely random games. More specifically, we tested the hypothesis that people will perceive themselves as luckier and subsequently will gamble more when they come close to a big loss than when they come close to a big win. We also tested the associated hypothesis that near big losses promote downward counterfactual thinking whereas near big wins promote upward counterfactual thinking.

\section{Method}

\section{Participants and design}

Participants were 30 male and female undergraduates enrolled in introductory psychology at the University of Alberta. They received partial credit toward a course requirement.

\section{Procedure and materials}

The experimenter greeted individual participants and reviewed the purpose of the research. Participants 
were told that the study concerned individual differences in knowledge about gambling, that they would answer a few questions about gambling, and play some games of chance. Participants then completed a brief questionnaire (e.g., "what is the most popular place for gambling in the world?") that supported the cover story.

The participant was then told that (s)he would soon enter another room to play various games of chance. The experimenter gave the participant 5 tokens, each of which was worth $\$ 0.20$. To enhance the meaningfulness of the gambling task, the experimenter said:

Just like any gamble you will have a chance to win more tokens, and hence more money; however, there is also a chance that you may lose all your tokens. At the end of the study, if you have any tokens left, you will be allowed to exchange them for real money... [that]... you will be allowed to keep.

The participant was then escorted to an adjacent room and was seated in front of a computer that displayed a slot machine style wheel-of-fortune game. The wheel was divided into seven sections. In the near big loss condition the sequence of sections was: 70 tokens, 15 tokens, 5 tokens, Bankrupt, 10 tokens, 15 tokens, 5 tokens. In the near big win condition the sequence was: Bankrupt, 15 tokens, 5 tokens, 70 tokens, 10 tokens, 15 tokens, 5 tokens. A "spin" button was located just below the wheel. Clicking this button set the wheel in motion, so that the sequences moved from the bottom of a window to the top of the window. A red payoff line was positioned horizontally in the middle of the window. In both conditions, three of the seven sections were visible in the window at any given time the wheel was spinning. The wheel spun rapidly at the onset of the spin and then gradually decreased in speed. In the near big loss condition, the wheel appeared ready to stop with the payoff line on the Bankrupt section but continued moving until the leading edge of the 10 token payoff section crossed the payoff line. Similarly in the near big win condition, the wheel reached its lowest speed on the 70 token Jackpot segment, but did not stop until the leading edge of the 10 token segment crossed the payoff line.

When the wheel stopped spinning, the experimenter approached the computer ostensibly to check the outcome. The experimenter then approached a table on the other side of the room, gathered 10 tokens, orally counted them individually, and handed them to the participant. The participant was then asked to approach a roulette table. The standard roulette wheel consisted of 38 slots, individually numbered 0,00 , and $1-36$ (the numbers are not arranged consecutively and alternated between red and black). The numbers, and the red-black wagering options, were represented on a green felt betting layout.
The participant was told that (s)he would place a bet on whether the roulette ball would land on a red or a black number. The participant was informed that the payout would be $1-1$, so that if all 15 tokens were placed on red and the ball landed on red, 15 tokens would be won, yielding a total of 30 . If, however, all 15 tokens were placed on red and the ball landed on black the original bet would be lost and no more games of chance could be played. The experimenter explained that (s)he would operate the game by spinning a small ball along the inner edge of the roulette wheel in the opposite direction of the wheel's spin. (S)he instructed the participant to make his or her bet before the wheel was spun. Once the bet was placed, and before the ball was spun, the participant completed a post-experimental questionnaire (described in the next section). The participant was then informed that the roulette game actually would not be played. (We stopped the procedure so that no participant would lose any money and each participant would leave the laboratory an equal winner). As a manipulation check, the participant was asked whether (s)he could recall the outcome of the wheel-of-fortune spin and the number directly above where the wheel had landed. All participants had perfect memory for these numbers. The participant was then probed for suspicion and debriefed.

\section{Dependent measures}

The post-experimental questionnaire consisted of first a measure of counterfactual thinking adapted from Markman et al. (1995) and then the Belief in Good Luck scale (BIGL; Darke \& Freedman, 1997). The counterfactual measure asked participants to list three ways in which the outcome of the wheel-of-fortune could have been different. The BIGL is a 12 -item individual difference scale designed to assess people's belief about luck. Although the scale was developed to measure stable trends in beliefs, it can be used as a dependent measure of transitory changes in the extremity of luck understood as a personal quality (Wohl \& Enzle, 2002). The questionnaire consists of 6-point Likert scale items anchored at 1 (strongly disagree) and 6 (strongly agree). For example, item 3, 8, and 12 ask, "I consider myself to be a lucky person," "Luck works in my favor," and "Luck is nothing more than random chance," respectively. Higher composite scores reflect increasing belief in personal luck.

\section{Results and discussion ${ }^{1}$}

Table 1 shows the means, $t$ values, and $p$ values for all dependent measures.

\footnotetext{
${ }^{1}$ The effects reported in this section were replicated even more strongly in a separate experiment that did not include the intervening behavior measure.
} 
Table 1

Dependent measures for Experiment 1

\begin{tabular}{lclll}
\hline & $\begin{array}{l}\text { Near big } \\
\text { loss } M\end{array}$ & $\begin{array}{l}\text { Near big } \\
\text { win } M\end{array}$ & $t$ & $p$ \\
\hline BIGL scale & 41.13 & 33.87 & 2.51 & $<.02$ \\
Number of tokens bet & 5.67 & 3.93 & 2.84 & $<.01$ \\
Counterfactual type & -0.47 & 0.13 & 2.08 & $<.05$ \\
\hline
\end{tabular}

\section{Personal luck and gambling behavior}

As predicted, participants in the near big loss condition perceived themselves to be personally luckier than participants in the near big win condition. Analysis of the Belief in Good Luck Scale scores showed that participants who experienced a near big loss on the wheelof-fortune expressed a greater belief in personal luck than did those who experienced an earlier near big win. Furthermore, we had predicted that people's self-perceptions of luckiness would influence their betting behavior. Consistent with this effect, participants in the near big loss condition bet more tokens on the subsequent game of roulette than did those in the near big win condition. Not surprisingly, the BIGL and number of tokens bet significantly correlated with each other, $r=.63, p<.001$.

We then tested mediation of gambling behavior by self-perceived personal luck following the procedure described by Baron and Kenny (1986). As reported above, we know that the near outcome independent variable significantly affected both self-perceived personal luck and gambling behavior and that personal luck and betting are significantly correlated. But is personal luck merely epiphenomenal or does it causally affect gambling? We regressed number of tokens bet on both the BIGL scale and near outcome conditions. The result of this analysis indicated that the effect of near outcome conditions on betting was no longer significant when number of tokens bet was regressed on both BIGL and near outcome conditions, $t(27)=1.57, p>.13$. Thus, there is strong evidence that self-perceived personal luck mediated gambling behavior.

\section{Counterfactual thinking}

The coding scheme for the direction of the first counterfactual listed by participants was as follows: $+1=$ upward counterfactual; $0=$ no counterfactual; $-1=$ downward counterfactual. An example of a response coded as an upward counterfactual was "I almost landed on the big one," and "I could have gone bankrupt" was an example of a counterfactual coded as downward. Two independent judges coded for counterfactual direction. The inter-judge agreement rate was $100 \%$. Consistent with established practice in this area (e.g., Kahneman \& Tversky, 1982; Markman et al., 1995), only the first counterfactual generated by the participant was analysed. A two-tailed $t$ test yielded a significant effect for direction of counterfactuals. As in previous research (e.g., Markman et al., 1995), participants in the near big win condition generated predominantly upward counterfactuals, whereas participants in the near big loss condition generated predominantly downward counterfactuals.

We also considered the possibility that counterfactual thoughts mediated self-perceived luck (rather than perceptions of luck being directly produced by the near win and loss experiences). The correlation between these two variables was negligible, $r=-.18, p>.34$. Likewise, there was no evidence that counterfactual thought mediated gambling behavior, $r=-.27, p>.16$.

\section{Experiment 2: Other types of near wins and losses and the question of affect}

Experiment 1 provided evidence that, perhaps counterintuitively, people who experience a near loss in a game of chance feel relatively luckier than people who experience a near win. It also showed that people who experienced the near loss subsequently gambled more than people who experienced the near win. These results closely matched our hypothesis that a near loss would result in people feeling relatively lucky to have escaped such a negative possible world (i.e., losing all their money), thus leading to an increased willingness to gamble. However, in Experiment 1, there was no control condition in which neither a near win nor a near loss occurred. Thus, the question remains of exactly where these effects come from. That is, do near wins and near losses both contribute to the effect? Experiment 2 included a control condition in order to examine this question.

Experiment 2 was also designed to address an interesting issue about the potential role of affect in near outcome situations (cf., Markman \& Tetlock, 2000; McMullen, 1997; Medvec, Madey, \& Gilovich, 1995; Roese, 1994). It could be the case that our particular near wins and losses created somewhat unique emotional reactions that might not characterize other types of near wins and losses. For example, our near loss in Experiment 1 (where the wheel just passed through Bankrupt to land on 10 tokens) might have produced a positive "plucked from the jaws of defeat" experience. Our near win in Experiment 1 (where the wheel just passed through Jackpot to land on 10 tokens) might have produced a negative "I had it and lost it" reaction. Perhaps, then, participants in the near loss condition experienced relatively more positive affect than did those in the near win condition. Such a difference in affect would then constitute an alternative explanation for the effects of near wins and losses on future gambling.

One way to resolve this possible conflation is to test other near wins and losses that would generate different 
emotional reactions than might have occurred in Experiment 1 , but which would have the same implications we described for self-perceived personal luck. For example, suppose that we arranged a new near loss experience so that the wheel slows down in the 10 token section and almost lands in Bankrupt; fear and negative affect would be more likely than positive affect. Imagine a new near win experience in which the wheel slows down in the 10 token section and almost lands in Jackpot; participants might feel empowered about engaging in future gambling activity because of the thrill they received from nearly winning. We included precisely these conditions in Experiment 2, and refer to them as run-to near win and loss experiences to differentiate them from the run-from near experiences in Experiment 1. Although these run-to experiences are likely to generate different emotions, note that they still possess the features we regard as critical to our hypothesis about personal luck and gambling. In both runfrom and run-to near loss conditions, the gambler's wish to avoid going Bankrupt is fulfilled, thereby enhancing perceptions of personal luck. In both run-from and runto near win conditions, the gambler's wish to land on the Jackpot is thwarted, thereby diminishing perceptions of personal luck.

\section{Method}

\section{Participants, design, and procedure}

Participants were 100 male and female undergraduate students enrolled in introductory psychology classes at the University of Alberta. They received partial credit toward a course requirement. Participants were randomly assigned among the five experimental conditions, including a run-from near big loss, a run-from near big win, a run-to near big loss, a run-to near big win, and a control condition.

The procedure for Experiment 2 was identical to that for Experiment 1, except for the addition of the three new conditions. In the run-from near big loss condition (identical to the near big loss condition in Experiment 1), the wheel appeared ready to stop with the payoff line on the Bankrupt section but continued moving until the leading edge of the 10 token payoff section crossed the payoff line. Similarly in the run-from near big win condition (again, the same as the near big win condition in Experiment 1), the wheel reached its lowest speed on the 70 token Jackpot segment, but did not stop until the leading edge of the 10 token segment crossed the payoff line. In the new run-to big loss condition, the wheel slowed down on the 10 token section and stopped just before the Bankrupt section. In the new run-to near big win condition, the wheel slowed down on the 10 token section and stopped just before the Jackpot (70 token) section. In the control condition, the wheel spun very fast and came to a sudden stop in the center of the 10 token section (the sections above and below the 10 token section were not visible). The same questionnaire used in Experiment 1 was used in this experiment with the addition of a measure of affect: "I am currently feeling" anchored at (1) sad and (7) happy.

\section{Results and discussion}

Table 2 shows the means, $F$ values, and $p$ values for all dependent measures.

\section{Personal luck and gambling}

To compare the no-near-outcome control condition with the factorial design conditions, one-way ANOVAs were conducted on all five conditions. ${ }^{2}$ As expected, this ANOVA showed a significant treatment effect on the Belief in Good Luck scale. Tukey's HSD post hoc test revealed that participants in the run-from near big loss and run-to near big loss (which are equivalent, $p>.87$ ) expressed a significantly greater belief in personal luck than did participants in the run-from near big win, runto near big win, and control conditions (which are equivalent, $p>.36$ ), $p \mathrm{~s}<.05$. There was also a significant treatment effect on number of tokens bet at the game of roulette. Tukey's HSD post hoc test revealed that number of tokens bet by participants in the runfrom near big loss and run-to near big loss (which are equivalent, $p>.73$ ) bet significantly more of their tokens than did participants in the run-from near big win, run-to near big win, and control conditions (which are equivalent, $p>.43$ ), $p$ s $<.002$. Thus, type of near outcome only had a significant impact when participants experienced a near big loss as opposed to a near big win. The differences within type of near loss or within type of near win were nonsignificant. Furthermore, as with all our other dependent measures, the near big win conditions and control condition were indistinguishable.

As in the first experiment, we tested for mediation of gambling by self-perceived luck. For this analysis we did not include the control condition, because participants in that condition did not experience a near outcome. Recall that the wheel-spin procedure for control condition participants involved showing them only their outcome while hiding adjacent outcomes. Including the control condition in a test of mediation by near outcome variable would thus make no sense because no near outcome was experienced. As required for a demonstration of mediation, two-way ANOVAs (near win vs. near loss $\times$ run-to vs. run-from) yielded significant near

\footnotetext{
${ }^{2}$ Two-way ANOVAs (run-to vs. run-from outcome $\times$ near-win vs. near-loss) also were conducted on the measures. In each case where the one-way ANOVA including the control condition showed differences between near win and near loss conditions, the two-way ANOVA yielded a significant main effect as well. No other effects in these factorial ANOVAs were significant.
} 
Table 2

Dependent measures for Experiment 2

\begin{tabular}{|c|c|c|c|c|c|c|c|}
\hline & \multicolumn{2}{|l|}{ Near big loss } & \multicolumn{2}{|l|}{ Near big win } & \multirow{2}{*}{$\begin{array}{l}\text { Control } \\
M\end{array}$} & \multicolumn{2}{|c|}{ One-way ANOVA } \\
\hline & Run-from $M$ & Run-to $M$ & Run-from $M$ & Run-to $M$ & & $F$ & $p$ \\
\hline BIGL scale & 46.50 & 43.85 & 30.90 & 34.65 & 36.00 & 10.91 & $<.001$ \\
\hline Number of tokens bet & 7.10 & 6.35 & 2.80 & 2.85 & 3.85 & 21.55 & $<.001$ \\
\hline Counterfactual type & -0.55 & -0.75 & 0.75 & 0.60 & 0.35 & 19.48 & $<.001$ \\
\hline Affect & 4.75 & 5.20 & 5.10 & 5.15 & 5.35 & 0.78 & $>.54$ \\
\hline
\end{tabular}

outcome main effects on both the BIGL, $F(1,76)=$ $36.69, p<.001$, and number of tokens bet, $F(1,76)=$ $69.20, p<.001$. (No other effects were significant in these analyses.) As well, there was the requisite significant correlation between number of tokens bet and BIGL scores, $r=.58, p<.001$. We then regressed number of tokens bet on both the BIGL scale and the two near outcome experiences (i.e., near wins and near losses). For purposes of this analysis, we collapsed across run-to and run-from types of near outcomes given that the run-to and run-from forms did not differ on our dependent measures. The regression analysis indicated that the effect of near outcome conditions on betting was no longer significant when number of tokens bet was regressed on both BIGL and near outcome conditions, $t(77)=1.04, p>.30$. Therefore, as in Experiment 1 , there is evidence that self-perceived personal luck played a mediational role in subsequent gambling.

\section{Counterfactual thinking}

A one-way ANOVA, including all five conditions, yielded a significant treatment effect on direction of counterfactuals. Participants in the run-from near big win, run-to near big win, and control conditions generated predominantly upward counterfactuals, whereas participants in the run-from near big loss and the run-to near big loss conditions generated predominantly downward counterfactuals. Tukey's HSD post hoc test revealed that there was significant differential focus on possible worlds generated between the near big loss conditions and the near big win and control conditions, all $p \mathrm{~s}<.002$. There was, however, no significant difference in the extent to which participants focused on better possible worlds between the conditions in which upward counterfactuals were generated, $p>.36$. Likewise, there was no significant difference in the extent to which participants focused on worse possibility worlds between conditions in which downward counterfactuals were generated, $p>.89$. Thus, at least in terms of the types of counterfactuals generated, participants in the new type of near outcome conditions (i.e., run-to near outcomes) responded in a like-manner to their old type of near outcome counterparts (i.e., run-from near outcomes). Perhaps more importantly, though, is the fact that participants in the control condition generated upward counterfactuals. That is, participants in the control condition responded to the experimental manipulation in a similar fashion to those participants in the near big win conditions.

We also examined the possible mediational role of counterfactual thoughts on self-perceived luck and gambling behavior. As with our examination of mediation by personal luck, we excluded the control condition from consideration because participants experienced no near outcome. The correlation between counterfactual thoughts and personal luck was negligible $r=-.17$, $p>.13$, as was that between counterfactual thoughts and gambling behavior, $r=-.22, p>.05$. Thus, counterfactual thoughts seem to have no effect on selfperceived luck and gambling.

\section{Affect}

We included two means of examining the potential influence of affect on gambling in our near experience paradigm. One was the inclusion of both run-to and run-from near outcomes in Experiment 2, because the types of outcomes seem to implicate differential emotional consequences. As we have seen, however, both types of near outcomes produce the same effects on perceived luck and gambling. The second method we included was a direct measurement of affect. One-way ANOVA on our measure of affect revealed no difference in mood between participants in the run-from near big loss, the run-to near big loss, the run-from near big win, run-to near big win, or control conditions. Inspection of the means reveals that all participants were above the midpoint on our scale, indicating that all participants, regardless of condition, were in a slightly positive mood. The lack of significant differences in affect should not come as a surprise. Every participant achieved a positive outcome irrespective of the near outcome experienced. At the conclusion of the experimental session, every participant won three dollars-a situation that would understandably lead to positive affect.

\section{General discussion}

The results from the two experiments provide good support for our predictions. Our starting point was the question of who would gamble more, a person who nearly won a relatively large sum or a person who nearly 
lost everything. We suggested that it would be the person who was left with the greater sense of being lucky after these experiences. We predicted and found that it is the person who nearly loses everything who feels relatively lucky (cf. Teigen, 1995, 1996), and it is this person who subsequently gambles more.

We noted earlier that the implications of near wins and losses at gambling previously have been approached mainly from the perspective of counterfactual thinking (e.g., Roese, 1997). Our analysis of these experiences in terms of perceptions of personal luck and future gambling share some features of the processes that theoretically contribute to counterfactual thinking, but are distinct. Our predictions were based on selfperception processes that implicate personalized aspects of luck. That is, following a brush with a disastrous gamble, people should consider themselves lucky to have escaped unscathed. This self-relevant information then should enhance their general perceptions of the degree to which they possess the personal quality of luck. When just missing a big payoff, people should consider themselves not lucky enough to achieve the desired outcome. Near big winners' self-perceptions of personal luck should therefore be lower than those of near big losers. We also know from our results (and those of others, e.g., Markman et al., 1993) that these experiences result in the generation of predictable types of counterfactuals.

An interesting question is whether or not upward and downward counterfactuals are themselves responsible for self-perceptions of luck. It could be the case, for instance, that the near brush with loss results in the downward form of counterfactual ("I could have lost everything") which then affects self-perceived luck ("Having avoided the terrible loss, I must therefore be very lucky"). Alternatively, successfully willing (wishing) the wheel to avoid the Bankrupt could lead directly to the self-perception of having controlled, through personal luck, the gambling outcome. Our mediational analysis suggests that counterfactual thinking and selfperceived personal luck are independent outcomes of the near win and loss experiences. It appears that perceptions of personal luck follow directly from the near win and loss experiences. We also found that perceptions of personal luck did mediate future gambling behavior. This flow of causal events makes sense in terms of desire for control models. Games of pure chance deprive people of straightforward means of asserting control over outcomes. Belief in the unconventional skill of personal luck, however, provides people with a means by which they influence such outcomes (Wohl \& Enzle, 2002). This form of control belief would then affect future gambling. The luckier people feel, the more they will gamble. Note that contrasts with our control condition suggest that most of these effects are attributable to the luck enhancing effects of near losses.
Experiment 2 provided the opportunity to address the possible influence of affect on perceptions of luck and gambling behavior. We suggested that the specific forms of near loss and near win in Experiment 1 could have produced unique affective reactions that affected selfperceived luck and future gambling ("plucked from the jaws of defeat" for the near loss and "had it and lost it" for the near win). In Experiment 2 we introduced new near win and loss conditions designed to avoid confounded emotional reactions. These new conditions produced exactly the same results as our original near win and loss experiences. As well, our direct measure of affect showed no difference between near win and loss conditions. Affect appeared to play no discernable role in our results.

Our results contribute to an emerging picture of how people understand luck in purely random gambling situations. Wohl and Enzle (2002) proposed that how much luck a person believes (s)he has fluctuates as a result of transitory experiences, just as state anxiety can vary within the boundaries of a person's level of trait anxiety. Consistent with this reasoning, Wohl and Enzle (2002) found that people attempted to influence random events when situational cues suggested that they were personally lucky. In the present study, information relevant to self-perception processes, the lucky avoidance of a big loss, contributed to participants' self-ascribed state of personal luck that led to a strong desire to gamble more.

\section{References}

Baron, R. M., \& Kenny, D. A. (1986). The moderator-mediator variable distinction in social psychological research: Conceptual, strategic, and statistical considerations. Journal of Personality and Social Psychology, 51, 1173-1182.

Darke, P. R., \& Freedman, J. L. (1997). The belief in good luck scale. Journal of Research in Personality, 31, 486-511.

Johnson, M. K., \& Sherman, S. J. (1990). Constructing and reconstructing the past and the future in the present. In E. T. Higgins \& R. M. Sorrentino (Eds.), Handbook of motivation and cognition: Foundations of social behavior. New York: Guilford Press.

Kahneman, D., \& Tversky, A. (1982). The simulation heuristic. In D. Kahneman, P. Slovic, \& A. Tversky (Eds.), Judgment under uncertainty: Heuristics and biases. New York: Cambridge University Press.

Langer, E. J. (1975). The illusion of control. Journal of Personality and Social Psychology, 31, 311-328.

Markman, K. D., Gavanski, I., Sherman, S. J., \& McMullen, M. N. (1993). The mental simulation of better and worse possible worlds. Journal of Experimental Social Psychology, 29, 87-109.

Markman, K. D., Gavanski, I., Sherman, S. J., \& McMullen, M. N. (1995). The impact of perceived control on the imagination of better and worse possible worlds. Personality and Social Psychology Bulletin, 21, 588-595.

Markman, K. D., \& Tetlock, P. E. (2000). Accountability and closecall counterfactuals: The loser who nearly won and the winner who nearly lost. Personality and Social Psychology Bulletin, 26, 1213 1224 . 
McMullen, M. N. (1997). Affective contrast and assimilation in counterfactual thinking. Journal of Experimental Social Psychology, 33, 77-100.

McMullen, M. N., \& Markman, K. D. (2000). Downward counterfactuals and motivation: The wake-up call and the Pangloss effect. Personality and Social Psychology Bulletin, 26, 575584.

Medvec, V. H., Madey, S. F., \& Gilovich, T. (1995). When less is more: Counterfactual thinking and satisfaction among Olympic medalists. Journal of Personality and Social Psychology, 69, 603610.

Roese, N. J. (1994). The functional basis of counterfactual thinking. Journal of Personality and Social Psychology, 65, 805-818.

Roese, N. J. (1997). Counterfactual thinking. Psychological Bulletin, $121,133-148$.

Sanna, L. J. (1996). Defensive pessimism, optimism, and stimulating alternatives: Some ups and downs of prefactual and counterfactual thinking. Journal of Personality and Social Psychology, 71, 10201036.

Sanna, L. J. (1998). Defensive pessimism and optimism: The bittersweet influence of mood on performance and prefactual and counterfactual thinking. Cognition and Emotion, 12, 635-665.

Teigen, K. H. (1995). How good is good luck. The role of counterfactual thinking in the perception of lucky and unlucky events. European Journal of Social Psychology, 25, 281-302.

Teigen, K. H. (1996). Luck: The art of a near miss. Scandinavian Journal of Psychology, 37, 156-171.

Wagenaar, W. A., \& Keren, G. B. (1988). Chance and luck are not the same. Journal of Behavioral Decision Making, 1, 65-75.

Wohl, M. J. A., \& Enzle, M. E. (2002). The deployment of personal luck: Illusory control in games of pure chance. Personality and Social Psychology Bulletin, 28, 1388-1397.

Weiner, B. (1974). Achievement motivation and attribution theory. Morristown, NJ: General Learning Press. 